\title{
Dendritic cells: a spot on sialic acid
}

\author{
Hélio J. Crespo ${ }^{1,2}{ }^{*}$, Joseph T. Y. Lau ${ }^{2}$ and Paula A. Videira ${ }^{1}$ * \\ ' CEDOC - UC Imunologia, Faculdade de Ciências Médicas, Universidade Nova de Lisboa, Lisbon, Portugal \\ ${ }^{2}$ Department of Molecular and Cellular Biology, Roswell Park Cancer Institute, Buffalo, NY, USA
}

Edited by:

Deirdre R. Coombe, Curtin University,

Australia

\section{Reviewed by:}

Masato Kubo, Tokyo University of

Science, Japan

Jason Waithman, Telethon Institute

for Child Health Research, Australia

*Correspondence:

Hélio J. Crespo and Paula A. Videira, Department de Ciências Médicas,

CEDOC - UC Imunologia,

Universidade nova de Lisboa, Campo

dos Mártires da Pátria 130, Lisboa

1169-056, Portugal

e-mail: helio.crespo@fcm.unl.pt;

paula.videira@fcm.unl.pt
Glycans decorating cell surface and secreted proteins and lipids occupy the juncture where critical host-host and host-pathogen interactions occur. The role of glycan epitopes in cellcell and cell-pathogen adhesive events is already well-established, and cell surface glycan structures change rapidly in response to stimulus and inflammatory cues. Despite the wide acceptance that glycans are centrally implicated in immunity, exactly how glycans and their changes contribute to the overall immune response remains poorly defined. Sialic acids are unique sugars that usually occupy the terminal position of the glycan chains and may be modified by external factors, such as pathogens, or upon specific physiological cellular events. At cell surface, sialic acid-modified structures form the key fundamental determinants for a number of receptors with known involvement in cellular adhesiveness and cell trafficking, such as the Selectins and the Siglec families of carbohydrate recognizing receptors. Dendritic cells (DCs) preside over the transition from innate to the adaptive immune repertoires, and no other cell has such relevant role in antigen screening, uptake, and its presentation to lymphocytes, ultimately triggering the adaptive immune response. Interestingly, sialic acid-modified structures are involved in all DC functions, such as antigen uptake, DC migration, and capacity to prime T cell responses. Sialic acid content changes along DC differentiation and activation and, while, not yet fully understood, these changes have important implications in DC functions. This review focuses on the developmental regulation of DC surface sialic acids and how manipulation of DC surface sialic acids can affect immune-critical DC functions by altering antigen endocytosis, pathogen and tumor cell recognition, cell recruitment, and capacity for T cell priming. The existing evidence points to a potential of DC surface sialylation as a therapeutic target to improve and diversify DC-based therapies.

Keywords: dendritic cell, sialic acid, sialylation, lectins, host-pathogen interaction

\section{INTRODUCTION}

Immunological studies, nowadays, imply researchers have at least basic knowledge of glycobiology since, at some point of their study, researchers are faced with glycosylation-related features. Glycosylation is a post-translational modification of basically all the secreted and cell surface proteins, as well as of lipids. Thus, all contacts between cell surface and/or serum molecules are continuously accompanied by glycosylation. The immune response lays on innumerous contacts between cells and molecules, a good example being the case of immunological synapses, a junction that forms between $\mathrm{T}$ cells and specialized cells and the antigenantibody interactions. All the immune encounters have, with great probability, glycans occupying, and influencing the juncture. Thus, all self-asserted immunologist should consider to be (at least partially) glycobiologists.

Among the several cell types that constitute the immune system, dendritic cells (DCs) are key players. DCs survey the microenvironment where they are positioned in order to help correctly classify collected antigen information, in a "self" or "“foreign" category, and to respond accordingly. They carry antigen information from the infection site to the secondary lymphatic organs, presenting them to $\mathrm{T}$ cells, strongly potentiating a specific immune response against pathogens (Figure 1). The immune response is thus tremendously dependent on DCs and impairment of DC functions, as studied using animal models deficient for DC function-related molecules, or absence of DC populations, have been associated with infection or, oppositely, to a wide range of autoimmune diseases (1). DCs also play an important role in antitumoral immunity, whereupon specific cytotoxic $\mathrm{T}$ cells may be primed by DCs to respond against tumor cells. Investigating the underlying mechanisms of DC-pathogen or DC-host and -tumor cell interactions may help us to better comprehend the immune response in physiological and pathological events and to identify new targets for therapeutic intervention.

Dendritic cells show specific glycan patterns at cell surface, which are modulated during cell differentiation and respond to stimuli such as inflammatory cytokines and pathogens (2-4). Sialic acid is a sugar that frequently terminates glycan structures. Due to its terminal position and properties, sialic acid can mediate many immune processes such as host-pathogen recognition, migration, and antigen presentation, among other non-immune related processes. The addition of this sugar is mediated by a number of enzymes, the sialyltransferases, mainly located in the Golgi apparatus. Sialyltransferase expression is 
Precursor cell/pre-DC

(e.g. monocytes, pDCs)
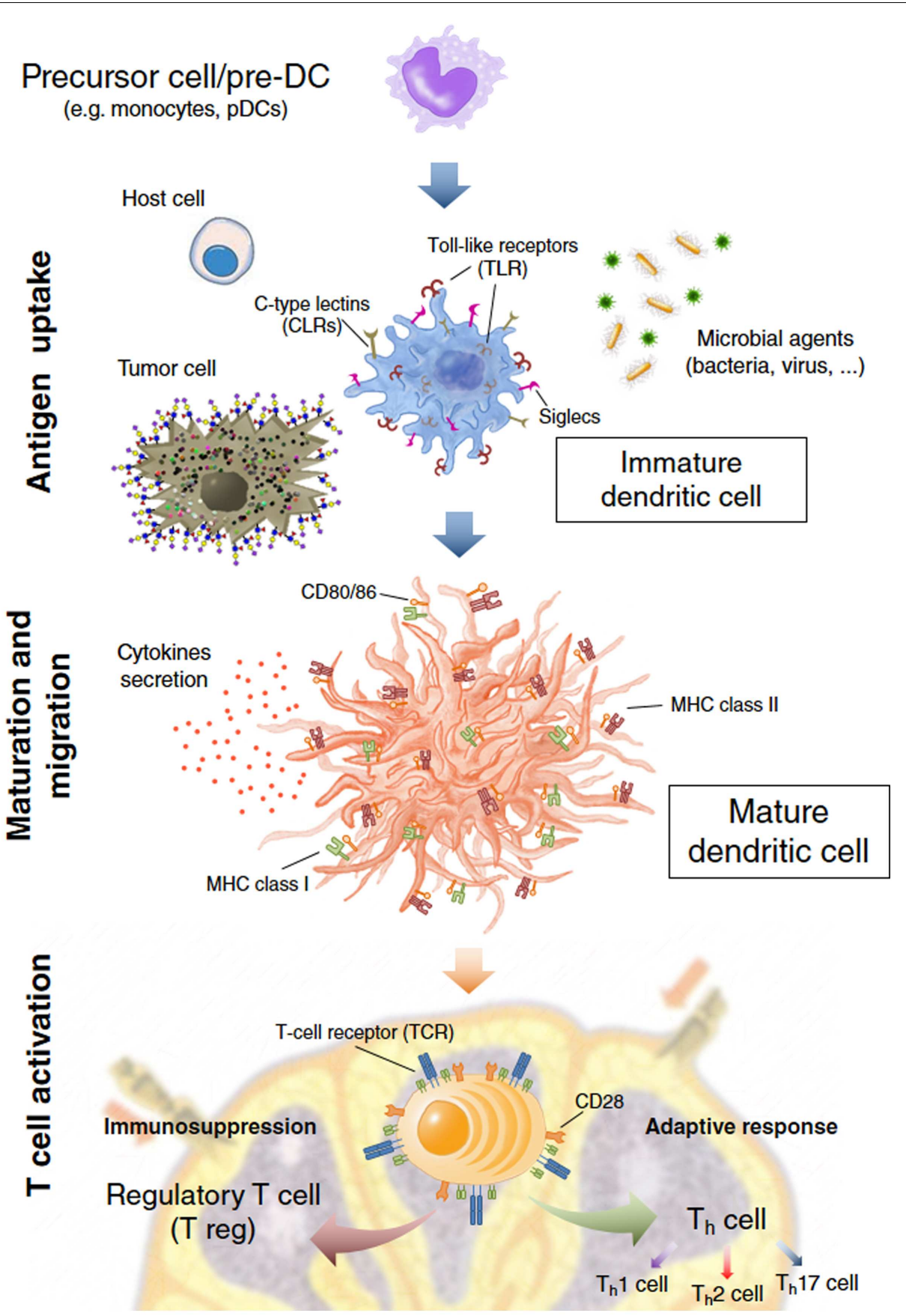

FIGURE 1 | Dendritic cell (DC) immune functions. DCs act on three main events: the antigen capture after interaction with host cells, microbial agents, and tumor cells by recognizing Pathogen-Associated Molecular Patterns (PAMPs) and self molecules through Pathogen Recognition Receptors (PRRs) and other cell surface receptors like Siglecs or C-type Lectins (CLRs); maturation and migration toward the secondary lymphoid organs; $T$ cell activation where DCs present the processed antigens to $T$ cells eliciting a specific and enduring response or tolerance from $\mathrm{T}$ cells. finely regulated during DC differentiation and maturation, concurring with the expression of sialylated structures $(3,4)$. In diverse immune events, the sialylated glycans will be recognized by lectins, i.e., carbohydrate-binding proteins that are expressed in other cells or by DCs. While promoting cell recognition by some lectins, the presence of specific sialic acids can actually switch off recognition by other lectins specific for asialylated glycans. Thus, glycan recognition by DC lectins may impact the DC immunobiological functions. Thus, a deeper understanding of sialic acid's influence in the DC immunobiology potentially leads to a better understanding of the immune mechanisms mediated by DCs. 
This review will focus on DC's glycoimmune processes, with special attention to the sialic acid-mediated ones and how they modulate the different DC functions. It includes an introduction of DCs' function and glycan recognition receptors, following a description of processes known to be mediated by sialic acid such as endocytosis, migration, priming of adaptive immune response, and pathogen/tumoral recognition.

\section{DENDRITIC CELLS}

Dendritic cells are part of the innate response and are essential to boost and/or regulate the adaptive immune response. They capture antigens in an earlier phase, process them "on the go" while migrating toward secondary lymphoid organs, such as lymph nodes, where they present, via major histocompatibility complex (MHC), the processed antigens to $\mathrm{T}$ cells and thus enacting an adaptive immune response. DCs can also present antigens to $\mathrm{B}$ cells, although by non-classical (non-MHC) mechanisms (5-7). Phenotypically, DCs are a heterogeneous population with different cell subsets, populating various organs. They can be broadly classified according the inflammatory status and differentiation state. Accordingly, conventional DCs are seen in a steady-state, that is, in the absence of infection and inflammation, and they can functionally be divided in two major types: migratory and nonmigratory (lymphoid-tissue-resident) DCs [reviewed by Shortman and Naik (8)]. A good example of the former are dermal DCs and Langerhans cells that mainly reside in skin tissues and after antigen contact, they mature and migrate to the draining lymph nodes - hence the "migratory" classification. Conventional, non-migratory DCs (like spleen DCs) reside in secondary lymphoid organs, where they constantly screen blood or lymph for pathogens. The variety of DCs inside both these groups is significant and adapted toward the tissue where they reside in the immature state. Regarding DC differentiation, both canonical myeloid and lymphoid hematopoietic progenitors contribute to the steady-state DC pool and, actually, DCs use unique and flexible developmental programs that cannot be categorized into the conventional myeloid or lymphoid pathway. The expression of the Fms-like tyrosine kinase 3 (Flt-3) molecules is characteristic of DC precursors, regardless of the myeloid or lymphoid lineage and DCs development is driven by Flt3-ligand (Flt3L) (8-14). Much interestingly, it was recently reported that conventional DCs are marked by the exclusive expression of the DNGR-1 (15).

Opposed to the conventional DCs, some populations are inflammatory or infection-derived DCs. These populations include the plasmacytoid DC (pDC) population, a first line of defense against microbial invasion. Functionally specialized in the detection of viral infections, pDCs, develop a fully differentiated DC phenotype after infection and secretion of type 1 interferon $(16,17)$. Other inflammatory DCs include the monocyte-derived DCs (moDCs), comprising the TNF- $\alpha$, inducible nitrous oxide synthase-producing DCs (Tip-DCs), a pathogenic subpopulation generated in an infection context (non-steady-state) [reviewed in Ref. (18)].

Dendritic cells constitutively uptake antigens in its surroundings as a surveillance measure (typical of the steady-state), fundamental to rapidly trigger the adaptive response against pathogens (inflammation) (19). DCs are, thus, naturally equipped with distinct means to uptake antigens, including: (1) receptor-mediated endocytosis, on which particles are endocytosed after cell surface receptor recognition; (2) macropinocytosis, or the non-selective endocytosis of solutes, a process constitutive in DCs and the major source of antigens for DC presentation (20); and (3) phagocytosis, the uptake of large molecules or cells, including virus, bacteria, protein clusters, apoptotic, and necrotic cells, which also involves specific membrane receptors. The uptake of foreign antigens usually trigger activation signals that will lead DCs to a mature phenotype, on which all the potential for antigen presentation and stimulation of the adaptive response immune cells is maximized.

Endocytosis is also fundamental in the maintenance of the selftolerance mechanisms since, at steady-state, self-antigens are normally endocytosed and posteriorly presented by DCs. Endocytosis of self-antigens does not usually induces significant maturation changes (21), thus contributing to turn DCs tolerogenic and promoting regulatory but not effector T cells. Nevertheless, it has been suggested that the presence of very small, time-persistent concentrations of foreign and more common antigens are responsible for the induction of tolerance to those same antigens. These toleranceinducing antigens are expressed by microorganisms present during the development of the immune system, such as commensal bacteria, flora members, and helminthes. The knowledge about these mechanisms raised the hypothesis that common microorganisms are able to regulate the immune system, the "old friends" hypothesis (22-24). These time-persistent antigens, thus shape our immune system to its present state, being presently not only tolerated but, in fact, needed in order to maintain the general tolerance balance. The "old friend" hypothesis complements the "hygiene" hypothesis stating, in brief, that the lack of immune challengers due to excessive hygiene is related to the growing number of autoimmune and hypersensitivity diseases that is observed in the developed countries, and not in the developing ones (24). Due to its key role in antigen uptake and presentation, DCs too may be involved in this mechanism of tolerance-induction toward these "old friends."

Dendritic cell maturation is the sum of all the phenotypical and functional changes occurring upon encounter with immune stimuli (i.e., antigens, cytokines, etc.) and it is crucial to enable DCs to effectively activate $\mathrm{T}$ cells. It is characterized by rapid downregulation of the antigen uptake process, acidification of lysossomal compartments, higher expression of MHC II molecules and of CD80 and CD86 co-stimulatory molecules, de novo or upregulated synthesis of DC-specific inflammatory cytokines (25). All these maturation and migration-changes are necessary hallmarks to enable DCs to perform antigen presentation and boosting $\mathrm{T}$ and B cell responses (26). It is also known that the molecular nature of uptaken antigens, as well as the cytokines to which DCs are exposed during the uptake process, are responsible for the modulation of the maturation process. This ultimately influences the differentiation of the DC-pulsed T cells into functionally distinct subtypes, namely, T helper type 1 or 2 (Th1 or Th2), T helper 17 (Th17), or regulatory $\left(\mathrm{T}_{\mathrm{reg}}\right)$ cells, actively shaping a future active or tolerance response.

The migration (or homing) of conventional or inflammatory DCs loaded with antigens to $\mathrm{T}$ cell niches (normally, secondary 
lymphatic organs) is a crucial step for the setting of effective immune responses. This process is characterized by chemokinemediated cell recruitment to the lymphoid target site and, activation of the surrounding tissues (27-29). Tissue activation helps to increase the cell adhesion to the endothelium, by inducing the expression of several adhesion molecules, of which integrins and selectins and its ligands are the most relevant elements.

From all the above observations, it is, thus, clear and generally accepted that DC functions rely on a complex set of mechanisms that involve DC differentiation, ontogeny, maturation, and permanent contacts with other cells and pathogens.

\section{PATHOGEN RECOGNITION BY DENDRITIC CELLS}

Pathogen recognition by DCs depends on the identification of distinct microbial patterns, not present in mammalian cells, but shared by most of the pathogenic microbial, known as "pathogenassociated molecular patterns" (PAMPs) (30, 31). They include bacterial and viral unmethylated CpG DNA, bacterial flagellin, peptides containing $N$-formylmethionine residues, lipoteichoic acids, and double-stranded and single-stranded viral RNA. A substantial part of PAMPs are glycan-containing ones, such as lipopolysaccharide (LPS), $N$-acetylglucosamine, peptidoglycan, and terminal fructose- and mannose-containing glycans, and glucan-containing cell walls from fungi.

Pathogen-associated molecular patterns are recognized by specific receptors named "pattern recognition receptors" (PRRs), with functions aggregating endocytosis and intracellular signaling. Examples of PRRs expressed by DCs include Scavenger receptors, Nod-like receptors, and C-type lectins (CLRs). However, perhaps, the most widely studied are the Toll-like receptors (TLRs), a growing family of 12 evolutionary conserved PRRs consisting of type 1 integral membrane glycoprotein with relevant role in the microbial response. The outcome of TLR recognition is the induction of intracellular signaling and consequent expression of antigen presentation molecules (MHC II molecules), co-stimulatory molecules (CD80/86, CD40), inflammatory and/or antiviral cytokines (such as TNF- $\alpha$, IL-12, IL-23, IFN $\alpha / \beta$ ), chemokines (i.e., IL-8, RANTES) (32, 33), thus enacting a powerful response against pathogenic microbes.

C-type lectins are another very relevant family of PRRs expressed by DCs (34). Being lectins, their main function is to recognize glycan structures and, in immunological context, they recognize pathogen-associated glycans or glycosylated selfantigens. In DCs, some CLRs of note include the DC-Specific Intracellular adhesion molecule-3 Grabbing Non-integrin (DCSIGN), CD207/Langerin, the Selectin family (discussed below), the Macrophage Galactose/ $N$-acetylgalactosamine-specific Lectin (MGL-1), Mannose Receptor (MR), DEC205, the Blood DC antigens 2 (BDCA 2), the Dendritic Cell Immunoreceptor (DCIR), the Dendritic Cell Immunoactivating receptor (DCAR), and Dectin$1 / 2 / 3$. In contrast to TLRs, all of these CLRs functionally bind glycan structures expressed by mammalian cells (except for Dectin$1 / 2 / 3$ that apparently only recognizes fungal and/or mycobacterial glycans), a fact demonstrating its potential role in both host and pathogen recognition (35). CLRs can also recognize and internalize pathogens for presentation without inducing DCs' maturation.
In fact, the CLR-mediated antigen uptake doesn't necessarily elicit a factual immune response, and may instead contribute to induce immunological tolerance (36). A downside of these phenomena is the potential immune escape of pathogens recognized via CLRs (35, 37-39).

Like CLRs, the Sialic acid-binding immunoglobulin-like lectins (Siglecs) can also recognize pathogens' glycoproteins and glycolipids thus also contributing to the host's innate immune responses. Siglecs specifically recognize sialic acid-containing glycans and as mentioned below they also play a relevant role in self recognition (40-43). The biological and immunological relevance of CLR and Siglec receptors will be discussed in detail in later sections.

Dendritic cells can also recognize and internalize microbes and its derivate particles by receptors that bind to opsonins in opsonized ("coated") microbes. Opsonization of microbes can occur in two forms: by coating with complement proteins or by binding of antibodies to antigens expressed on their surface. DC recognition of opsonized microbes is thus mainly mediated by complement receptors and Fc receptors and assures the capture of pathogens that might otherwise evade recognition by other DC receptors $(44,45)$.

Summarizing, DCs can interact in different ways with microbes, as well as with the host antigens, through panoply of receptors. This recognition initiate mechanisms that will induce or suppress a specific immune response. The DC recognition is thus considered to be of great relevance for the development of a suitable, specific immune outcome, dictating the balance tolerance/reactivity of the developing host-pathogen response.

\section{DENDRITIC CELLS-BASED THERAPY}

The current knowledge of DC immunobiology allowed several biotechnological and pharmaceutical companies to develop DC-based immunotherapies. Applications for DC-based therapy include a plethora of pathologies ranging from infectious and hypersensitivity diseases to malignancies. One strategy is the ex vivo upload of DCs with the antigen to turn them able to efficiently develop an efficient response against the antigen bearer (46-50). The best example of this strategy is the vaccination of cancer patients with DCs loaded with tumor antigens.

Other approaches include the use of specific antibodies targeting DC endocytic receptors that are used to force the upload of specific antigens toward that receptor. Antibodies are also used to block specific receptor-ligand interaction and consequent downstream signaling, counteracting for instance the negative immunomodulatory cues of the tumor microenvironment.

Dendritic cells have also been studied as targets of DNA vaccines encoding for antigens (51). Viral transduction not only targets antigens to DCs, but also induces intracellular pathways to modulate the immune response (52).

All these relatively recent drug-niche that exploits DC unique immune potential is proof of reconnaissance of DCs' cornerstone role in the immune system. Nevertheless, the DC-based therapies still face several hindrances to full application, mostly derived from the lack of full knowledge regarding pathogenesis/tolerance balance mechanisms, an area where glycosylation has been shown to have a relevant role. 


\section{GLYCOSYLATION AND SIALYLATION}

Glycosylation is the most frequent modification of proteins and lipids. The majority of glycans exist as membrane-bound or soluble glycoconjugates. One consequence of this fact is that all cells present at their surface a glycocalyx, that is, the full surfacecomplex of glycans, glycoproteins, and glycosylated lipids. The three main classes of glycoconjugates are glycoproteins, proteoglycans, and glycolipids and their synthesis occurs mainly in (but not limited to) the lumen of the endoplasmic reticulum and in the Golgi apparatus. In glycoproteins, the sugar chain is classified as $\mathrm{N}$ - or $\mathrm{O}$-linked, depending if the glycosidic moiety is linked to an asparagine (Asn) residue in the protein moiety or to a serine/threonine (Ser/Thr) residue, respectively.

The cell glycocalyx is the result of many factors. The most relevant one is probably the expression of the set of enzymes responsible for the synthesis and/or transfer of glycosylated structures, i.e., the glycosyltransferases. Also critical is the expression of enzymes responsible for the removal of glycans or entire structures from glycosylated molecules, i.e., the glycosidases. These two sets of enzymes work in a finely controlled balance both during the glycoconjugate synthesis at the Golgi apparatus. Both enzyme types can also be present in plasma membrane or soluble forms, with potentially relevant biological roles as we shall see in sections below (53-56).

Sialic acids are a large family of negatively charged, ninecarbon monosaccharides that are normally found at glycan terminal positions. They include $\mathrm{N}$-acetylneuraminic acid (Neu5Ac), $\mathrm{N}$-glycolylneuraminic acid (Neu5Gc), and 9-O-acetyl$\mathrm{N}$-acetylneuraminic acid (9-O-Ac-NeuAc). Human cells can only synthesize Neu5Ac. However, Neu5Gc can also be found in some tumor cells (57). Interestingly, some pathogens may express Neu5Ac, but Neu5Gc has never been reported to be synthesized by any pathogenic bacteria (58). This review will focus mainly on Neu5Ac and, for the sake of simplification, and we will strictly refer to Neu5Ac when using the term "sialic acids."

Sialyltransferases are a family of twenty glycosyltransferases that catalyze the addition of sialic acids to terminal non-reducing position of the oligosaccharide, transferring the sialic acid from the activated sugar donor CMP-Neu5Ac to different sugar acceptors (Table 1). Sialyltransferases normally locate at the Golgi apparatus as integral membrane proteins adding sialic acids to glycoconjugates during their synthesis. However, some sialyltransferases are also expressed as soluble enzymes (59) and sialyltransferase activity at plasma membrane has been reported in immune cells (54). Each sialyltransferase presents high selectivity toward its acceptor substrate. In vivo, competition between other sialyltransferases and glycosyltransferases' common substrates is observed and, as a result, the cell's sialylation status is the dynamic sum of transferase activities, Golgi localization, and concentration of activated sugar donors. Sialyltransferases depending on their specificities, can establish $\alpha 2,3-, \alpha 2,6-, \alpha 2,8$-linkages and can be organized in four families depending on linkage specificity and acceptor substrate: the ST3Gal family, catalyzing the addition of sialic acid to a terminal galactose of $O$-linked glycans and glycolipids in an $\alpha 2,3$-linkage; the ST6Gal family, $\alpha 2,6$-linking sialic acids to galactose residues of $\mathrm{N}$-glycans; the ST8Sia family, the only known sialyltransferases promoting the linkage to another sialic acid residue in $\mathrm{N}$ - or $\mathrm{O}$-glycans, in a $\alpha 2,8$-bond; and, finally, the ST6GalNAc family, adding sialic acid to terminal $\mathrm{N}$-acetylgalactosamine (GalNAc) residues of glycoproteins and glycolipids, in an $\alpha 2,6$-linkage (60). Thus, on the cell surface, sialic acid residues can be present in $\mathrm{N}$ - and $\mathrm{O}$-glycans in glycoproteins, as well as in gangliosides, i.e., a glycolipid containing one or more residues of sialic acid.

The overall sialic acid content of a cell is also regulated by the removal of sialic acid residues, catalyzed by the sialidase enzymes. Four known enzymes fit into this family, also known as the Neuraminidase family: Neu1, Neu2, Neu3, and Neu4. These sialidases are variedly distributed, with Neul located at the lysosomes and also expressed on the surface of diverse types of cells, Neu2 at the cytosol, Neu3 integrated in the cell membrane, and Neu4 being an intracellular protein. They are all exoglycosidases, i.e., they cleave terminal sialic acids, but have different substrate specificities: Neu1, Neu2, and Neu4 remove sialic acid residues from glycoproteins, Neu2 and Neu4 also cleaves sialic acids from glycolipids, and Neu3 preferentially hydrolyzes gangliosides. A list of human sialyltransferases and sialidases, their expression patterns in DCs, and their preferred acceptor and donor substrates, is shown in Table 1.

\section{SIALYLATION AND MODULATION OF THE IMMUNE RESPONSE}

The terminal position occupied by sialic acids on membrane and extracellular glycans puts them on the frontline during leukocyte communication and overall immune response. Sialic acids, on an immune perspective, can function in two (seemingly contradictory) major ways: as biological masks and as recognizable cell patterns (63). In the former way, sialic acid helps shield host cells from pathogen recognition. It also prevents autoimmune responses, by preventing complement deposition over cell surface. Furthermore, it was reported that, during acute phase inflammation, both soluble and cell surface sialic acid is increased, as a consequence of the increase in soluble and circulatory forms of sialyltransferases. Higher sialic acid is thus part of the acute phase response and it seems to protect cells against pathogens, and also helping the immune system distinguishing "self" from "nonself" antigens (64). ST6Gal-I is an example of sialyltransferase whose soluble expression is upregulated during inflammation and its expression has been used by some authors as a serological clinical marker for inflammation (65-67). Non-sialylated glycans are recognized by specific lectins, and the addition of sialic acid to its terminal position may blocklectin binding. As an example, the presence of $\alpha 2,6$-linked sialic acids on $N$-glycans blocks recognition by galectins (68), a family of $\beta$-galactoside-binding lectins that regulate diverse cell behaviors, such as cell adhesion, migration, proliferation, differentiation, transformation, apoptosis, angiogenesis, and immune responses (69-73). However, sialic acid masking can also be used by pathogens, as a mimicry tactic in order to evade the immune system. This is the case of some Trypanosoma spp. that have mutated ST3Gal sialyltransferases that act as trans-sialidases, transferring the host's sialic acid to coat themselves in order to evade host recognition $(74,75)$.

Opposed to the asialylated-glycan recognition, sialic acids can be recognized by several cell surface receptors, such as the 
Table 1 | Human sialyltransferases and sialidases.

\begin{tabular}{|c|c|c|c|}
\hline & Preferred saccharide substrate & Glycan specificity & Dendritic cell expression (cell status) \\
\hline \multicolumn{4}{|c|}{ SIALYLTRANSFERASE } \\
\hline ST3Gal-I & Gal $\beta 1,3$ GalNAc & O-glycan & Yes \\
\hline ST3Gal-II & Gal $\beta 1,3$ GalNAc & O-glycan & Yes (mature) \\
\hline ST3Gal-III & Galß1,3(4)GlcNAc & O-glycan, $\mathrm{N}$-glycan & Yes (mature) \\
\hline ST3Gal-IV & Gal $\beta 1,4(3) \mathrm{GlcNAc}$ & $N$-glycan, O-glycan & Yes (mature) \\
\hline ST6Gal-I & Gal $\beta 1,4 \mathrm{GlcNAc}$ & $N$-glycan & Yes \\
\hline ST6Gal-II & Gal $\beta 1,4 \mathrm{GlcNAc}$ & $N$-glycan & No \\
\hline \multirow[t]{2}{*}{ ST6GalNAc-I } & GalNAc $\alpha 1, O-S e r / T h r$ & O-glycan & No \\
\hline & Gal $\beta 1,3$ GalNAc $\alpha 1$, O-Ser/Thr & & \\
\hline ST6GalNAc-II & Gal $\beta 1,3$ GalNAc $\alpha 1$, O-Ser/Thr & O-glycans & Yes \\
\hline ST8Sia-I & Sia $\alpha 2,3$ Gal $\beta 1,4$ Glc-ceramide & Glycolipid & No \\
\hline ST8Sia-II & Sia $\alpha 2,3 \mathrm{Gal} \beta 1,4 \mathrm{Gl} \mathrm{cNAc}$ & N-glycan on NCAM & No \\
\hline ST8Sia-III & $\operatorname{Sia} \alpha 2,3 \mathrm{Gal} \beta 1,4 \mathrm{Gl} \mathrm{cNAc}$ & N-glycan on NCAM & No \\
\hline ST8Sia-IV & $(\text { Sial } \alpha 2,8)_{n} \operatorname{Sia} \alpha 2,3 \mathrm{Gal} \beta 1-\mathrm{R}$ & N-glycan on NCAM & Yes \\
\hline ST8Sia-V & GM1b, GT1b, GD1a, GD3 & Glycolipid & No \\
\hline ST8Sia-VI & $\mathrm{Sia} \alpha 2,3(6) \mathrm{Gal}$ & Sialic acid on O-glycan & Unknown \\
\hline \multicolumn{4}{|l|}{ SIALIDASES } \\
\hline \multirow[t]{2}{*}{ Neu1 } & $\operatorname{Sia} \alpha 2,3$ & Oligosaccharides & Yes \\
\hline & $\operatorname{Sia} \alpha 2,6$ & Glycopeptides & \\
\hline Neu2 & $\operatorname{Sia} \alpha 2,3$ & Oligosaccharides & No \\
\hline
\end{tabular}

Preferred substrates for each enzyme and expression pattern in human dendritic cells are indicated. Data was based on (2, 4, 61, 62).

? stands for "unknown" regarding the cell status (whether mature or immature).

previously mentioned CLRs and Siglecs $(41,76)$. Siglecs are sialic acid-recognizing proteins that, albeit structurally similar, are commonly organized in two categories: (i) one comprises the CD22 family [including CD22 (or Siglec-2), sialoadhesin (or Siglec-1), myelin-associated glycoprotein (MAG or Siglec-4), and Siglec15]; and (ii) the CD33-related family comprising CD33 (or Siglec 3), Siglec-5, -11, -14, and -16 in humans, all chiefly expressed in myeloid and lymphoid cells $(63,77)$. Siglecs recognize and bind ligands present not only in other cells (viz., in trans) but also on the same cell (in cis). Many Siglecs present one or two intracellular immunoreceptor tyrosine-based inhibitory motifs (ITIMs), classically described as being involved in signaling to regulation-inducing pathways, or intracellular tyrosine-based activation motifs (ITAMs), involved in the initiation of activation signaling pathways. Hence, Siglecs have a decisive role in regulating, positively or negatively, immune responses such as inflammation or tissue damage by actively discriminating between self-associated molecular patterns (SAMPs) and PAMPs $(41,63,78,79)$.
Studies using mice deficient for selected $\alpha 2,3-$ and $\alpha 2,6$ sialyltransferases have provided evidence confirming the importance of sialic acid in immune processes (80-82). ST6Gal-I KO mice were reported as presenting impaired humoral immune response, namely, by reduced concentration levels of circulating and surface IgM, impaired B cell proliferation in response to various activation signals and impaired antibody production following contact with antigens (80). CD22, one of the first described Siglecs (83), was later shown to recognize ST6Gal-Imediated glycans, functionally regulating several B cell functions and survival mechanisms (84). Other ST6Gal-I KO mice studies have also revealed that soluble forms of ST6Gal-I have a relevant role in myelopoiesis during acute inflammation, namely, by limiting it, thus avoiding uncontrolled excessive neutrophilic and eosinophilic inflammatory responses $(59,85,86)$. Using ST3GalI KO mice, on the other hand, it has been shown that $\alpha 2,3$ sialylated $\mathrm{O}$-glycans are required for $\mathrm{CD}^{+} \mathrm{T}$ cell homeostasis and survival (82). 
These are only few examples on how sialic acids influence immune-relevant processes. Other examples include roles in hostpathogen interactions, regulation/modulation of the acute phase response and influence in the progression and differentiation of human malignancies.

\section{DENDRITIC CELLS AND SIALIC ACID}

As above mentioned, DCs play a role of enormous relevance in the immune system. Ever since Dr. Steinman and co-workers first described these cells (87-91), there has been an effort to fully characterize their immunobiology, and as part of those efforts, the relevance that glycosylation may have on it. The characterization of the DC's "glycome" ("sialome" included) and its functional impact on the DCs immunobiology and, of course, on the immune system has been a work in progress. There are many questions still open, with many potential clinical applications.

\section{SIALYLATION IN DENDRITIC CELLS}

In human DCs, the sialylation profile of inflammatory DCs has been the most studied. This comes as the result of two factors: first, they are the most frequent population of DCs and, second, in more practical terms, they are the easiest subset to obtain in vitro with human moDCs being a widely used human conventional migratory and inflammatory DC model. Other vertebrate DC models rely on the obtainment of DCs by differentiation of bone marrow extracts or, more specifically, CD $34^{+}$hematopoietic precursors myeloid lineage (92).

Immature moDCs present a high sialylation content, namely $\alpha 2,3-$ and $\alpha 2,6$-sialylated glycoproteins, when compared to its monocyte precursors $(4,93)$. This has been reported by different teams that used plant lectins from Sambucus nigra and Maackia amurensis, preferably recognizing $\alpha 2,6$-linked sialic acid linked to lactosamine (Neu5Ac $2,6 \mathrm{Gal} \beta 1,4 \mathrm{GlcNAc}-$ ) in $N$-glycans and $\alpha 2,3$-linked sialic acid linked to lactosamine (Neu5Ac $\alpha 2,6 \mathrm{Gal} \beta 1,4 \mathrm{GlcNAc}-$ ), respectively.

Quantitative Real-Time PCR and microarray analysis has shown that both sialyltransferases and sialidases undergo significant gene expression variation during differentiation and maturation $(4,62,93,94)$. In particular, a significant upregulation of the ST3Gal-I and ST6Gal-I genes occurs during moDCs' differentiation that correlates with an increase of enzymatic activity by these two enzymes. Increased phenotypic change in $\alpha 2,3-$ and $\alpha 2,6$-sialylation (4) during myeloid lineage-committed differentiation indicates these two sialyltransferases as the major contributors to the biosynthesis of $\alpha 2,3-$ and $\alpha 2,6$-linked sialic acid-containing glycan structures specific for moDCs, with potential functional relevance. There are, however, other potentially relevant sialyltransferases that should not be discarded, such as ST3Gal-IV and -VI, being described as essential for the synthesis of the adhesion-related sialyl-Lewis $\mathrm{x}\left(\mathrm{sLe}^{\mathrm{x}}\right)$ antigens. Regarding sialidases, modulation during moDCs' differentiation is similarly observed, with Neu1 and Neu3 being significantly upregulated during this process (62). Maturation of moDCs leads to an increase of $\alpha 2,3$-sialylation and a decrease of $\alpha 2,6$-sialylation (2, 4,93 ) although the reported variations are stimulus-dependent processes, and correlated with the sialyltransferases and sialidases activity.
While the functional impact of these observed sialic acid changes has to be further elucidated, there is already some evidence that these variations are biologically relevant, as it will be discussed further on in this review.

\section{SIALIC ACID-RECOGNIZING DENDRITIC CELL RECEPTORS}

Sialic acid-containing glycans expressed by DCs are the target of receptors, such as Siglecs, being the largest represented family. Recognition of DC sialylated glycans has functional implications: examples include a recognition mechanism of high $\alpha 2,6$-sialic acid content of immature and tolerogenic DCs by inhibitory Siglecs expressed by effector $\mathrm{T}$ cells as a host-tolerance-inducing mechanism (93), or the observed increased binding of Siglecs-1, -2, and -7 correlating with the higher sialic acid content of mature DCs (2). All this gathered evidence point to an even more promising, relevant role of Siglec-mediated immunobiological processes involving DCs and other leukocytes, but still to be unraveled and requiring, thus, further studies.

Besides being recognized by Siglecs through their expression of glycans, DCs express themselves Siglecs enabling them to also recognize sialylated structures. MoDCs and blood-circulating DCs [namely pDCs, CD1a ${ }^{+}$, and CD141 ${ }^{+}$DCs (95)] express Siglec$1,-2,-3,-5,-7,-9,-10,-14$, and $-15(2,43,78,96)$, while pDCs have a more restricted pattern and apparently only express Siglec-5 (43). Siglecs, with the exception of Siglec-14 and -15, expressed by DCs present ITIM motifs in their cytosolic portion and are therefore mainly involved in inhibiting activation signals and have an immunoregulatory function $(40,41)$.

The concentration of sialic acids on surfaces of human cells is very high; for example, Stamatos and colleagues estimated that DCs had $8.9 \mathrm{nM}$ per $5 \times 10^{6}$ cells, which correspond to nearly $10^{18}$ sialic acid molecules per cell (62).

Therefore, it is possible that the majority of Siglecs expressed at DC surface bind in cis, i.e., to sialic acids at their own cell surface. The cis interaction will have primacy over the trans interactions, the only exception being sialoadhesin, which has an extended structure, projecting their binding site away from plasma membrane and being therefore involved in trans interactions (97).

Siglec interactions in cis can be released by sialidase activity, either extrinsic for instance from pathogens or intrinsically due to the activity of endogenous sialidases $(40,98)$. Since DCs ultimate function is to immunomodulate T cells and (to some extent) B cells, Siglecs potentially play a largely relevant role in hosttolerance mechanisms $(2,43,99)$. Chen and co-workers reported Siglec-10 as involved in helping distinguish TLR-recognized danger-associated molecular patterns (DAMPs) - generated during cell/tissue damage or even regular cell lifecycle - from PAMPs, thus controlling inflammation (100). There are known examples of $\mathrm{T}$ cell activation where DC Siglecs have a relevant role in inducing Th1 and Th2 responses, as is the case of DC Siglecs- 1 and -7 trans recognition of $\alpha 2,3$-sialic acids and $\alpha 2,8$-polisialic acids, respectively, in mimicked GM1a and GDla (Siglec-1 recognized) and GD1c (Siglec-7 recognition) gangliosides included in Campylobacter jejuni's LPSs (101).

CD33-related Siglecs can function as endocytic receptors that are important in the clearance of sialylated antigens. On the other hand, many pathogens are able to express appropriate sialic acids 
themselves (102-105). Pathogen's sialic acids may interfere with DC functions such as endocytosis $(43,106)$ thus helping DCs to internalize and further present pathogen's antigens. This, however, may also open an opportunity window for pathogens to modulate DCs' immune functions (by binding to immunoregulating Siglecs) or even use DCs as vectors (i.e., "Trojan horses") for infection of other immune system cells, such as HIV using Siglec-1 as a gateway-receptor for DC entry and posterior transmission to $\mathrm{CD}^{+} \mathrm{T}$ cells (107). However, a safety mechanism may be present: Siglec-15 can act as an activation receptor balancing the negative signaling triggered after recognition of sialylated pathogens (viz., enveloped viruses) through inhibitory Siglecs (78).

\section{DENDRITIC CELL SIALYLATION AND ENDOCYTOSIS}

The sialic acid's role on endocytosis has long been studied on the perspective of the pathogen. Besides the already referred transsialidase bearing T. cruzi parasite, it is also known that several bacteria developed sialic acid-masking mechanisms in order to escape immune surveillance and/or response (108). Recent discoveries, however, hinted that sialic acid's role in these immune processes goes far beyond than "just" being an antigen, with a functional impact on the innate immune phase cells as well, like DCs.

As previously mentioned DCs are functionally well prepared to endocytose pathogens, in order to process and present them to the adaptive immune response cells $(20,109,110)$. Using two different approaches - sialidase treatment of moDCs and bone marrowderived DCs (BMDCs) from sialyltransferase KO mice, it has been determined the functional impact of sialic acid on macropinocytosis and phagocytosis. Asialylated DCs presented significantly reduced ovalbumin-macropinocytosis but increased phagocytosis levels (111). Similar results having been obtained using BMDCs from ST6Gal-I and ST3Gal-I sialyltransferase-deficient mice (3).

Sialic acid removal (or absence in BMDCs) has a positive impact over the DC maturation process, leading to higher expression of maturation markers. Hence, this effect should account for the observed reduction of macropinocytosis levels, since matured DCs tend to have decreased endocytosis ability (112). The observed increase in phagocytosis in asialylated immature and mature DCs (111) seems, therefore, to oppose the endocytosis reduction induced by maturation. It is documented, however, that mature DCs may continuously uptake antigens by phagocytosis and receptor-mediated endocytosis, even if always described in lower levels than immature DCs $(110,113)$. As no studies have been performed from a sialic acid point of view, this can account for novel, groundbreaking evidence adding to the well-established concepts of endocytosis. Another piece of this apparent puzzle lies in the DC cytoskeleton, which has to be adjusted to perform cellular extensions needed for phagocytosis. After sialidase treatment of DCs, a cytoskeleton disorganization is observed. In addition, the activity of two Rho GTPases - Racl and Cdc42 - that regulate, among other processes, the actin-dependent events of macropinocytosis and phagocytosis $(19,112,114-116)$ are downregulated, after sialidase treatment. This may justify the cytoskeleton disorganization and decreased macropinocytosis.

Hence, the fact that sialidase treatment accounts for the significant E. coli phagocytosis enhancement, in both sialidase-treated immature and mature DCs, is a process unrelated to maturation. Interestingly, the effect on phagocytosis seems to depend on the presence, in trans, of bacterial sialic acid (111), adding a potential involvement of Siglecs. Hence, sialidase treatment would release DCs' Siglecs from in cis ligands, making them available to bind to ligands in trans, such as sialic acid-containing glycans present in the E. coli cell wall. However further investigations are still needed to elucidate the underlying mechanisms.

Sialidase-induced activation of receptors is not a novel phenomenon. Receptors like TLR-4 are known to depend on the activity of membrane sialidase prior to LPS-induced activation: in mice, DC phagocytosis is activated by desialylation of surface receptors $(62,117,118)$. This evidence is in line with the already mentioned increased expression of sialidases, such as Neul during DCs differentiation and maturation (117). Furthermore, physiologically, cell surface sialic acid content is not exclusively cleaved by endogenous sialidases, since exogenous sialidase sources are also released by pathogenic bacteria or virus during the course of an infection. In the mouse model, it was reported that Neu1induced desialylation activates phagocytosis by macrophages and DCs (118). Also, cell surface desialylation by influenza virus sialidase stimulates the internalization of target virus by infected mouse macrophages (119).

Siglecs and TLRs fit perfectly in the recent model presented by Cabral and collaborators showing that sialidase treatment of DCs favors phagocytosis (111). Since they are receptors with both strong activating- and suppressive-inducing properties, with known roles in regulating immune responses and with the potential of becoming active after sialic acid removal by sialidases, they are also likely to account for the observed upregulation of both pro- and anti-inflammatory cytokines (111). Nevertheless, the referred receptor families may not be the only receptors affected by sialidase treatment in DCs as novel glycan-protein interactions are continuously being revealed, but further studies are in order to better elucidate the role of sialic acid in endocytosis.

\section{SIALYLATION AND DENDRITIC CELL MIGRATION}

Dendritic cell migration includes both DC recruitment to nonlymphoid tissue and homing to lymphoid organs.

When located within tissues, DCs may respond to proinflammatory cytokines and pathogens, which trigger maturation and DCs then migrate to lymphoid tissues via afferent lymphatic vessels, wherein they activate antigen-responsive T cells. Immature and mature DCs may also enter the blood and from there disseminate to non-lymphoid and lymphoid organs, thereafter returning to blood, thus undergoing cycles of recirculation. Therefore DCs have complex trafficking routes, allowing for dynamic reassortment of DCs, making the most of their capacity to uptake antigens and to encounter T cells to present antigens and activate them.

While, generally, the migratory processes are based upon mechanisms like adhesion and chemotaxis, some processes still show their own particularities. The extravasation of blood DCs to any tissue involves DC adhesion to endothelium and is dependent of selectin interactions with sialofucosylated glycans. The role of certain sialylated glycans as selectin ligands is one of the most recognized functions of sialic acid in the context of leukocyte recruitment (120). 
Selectins are CLRs expressed by platelets, endothelium, or leukocytes, hence taking their name: P-, E-, or L-selectins, although endothelial cells also express P-selectins.

All selectins recognize the sialic acid and fucose (Fuc) containing tetrasaccharide, where $\operatorname{sLe}^{\mathrm{x}}$ (Neu5Ac $\alpha 2,3 \mathrm{Gal} \beta 1,4[\mathrm{Fuc} \alpha 1,3]$ GlcNAc-) is the major prototype. Selectin ligands are expressed in most circulating immune cells and some endothelial cells during inflammation. They mediates essentially the rolling and tethering phase of cell transmigration over the endothelial cell surface (121). sLe ${ }^{\mathrm{x}}$ expression is well characterized in neutrophils and lymphocytes $(76,122)$ but only relatively approached in DC (123126). Recently, it was found that moDCs also express functional selectin ligands, based on their observations of moDC tethering and rolling over a P-, E-, and L-selectin immobilized surface (126). They observed decreasing tethering affinities (by decreasing order) toward P-, E-, and L-selectin, with similar lower rolling velocity on $\mathrm{P}$ - and E-selectins and the largest rolling velocity observed over L-selectins. These findings were in line with other studies using blood DCs and CD34 ${ }^{+}$-derived DCs $(125,127)$. Furthermore, the use of anti-sLe $e^{\mathrm{x}}$ antibodies on the rolling studies resulted in a significant binding inhibition, definitely proving that $s \mathrm{Le}^{\mathrm{x}}$ mediates the moDCs-selectin binding (126).

In order to properly function as a selectin ligand, $\mathrm{sLe}^{\mathrm{x}}$ must be expressed in carrier glycoproteins or glycolipids $(128,129)$. The only described sLe ${ }^{\mathrm{x}}$ carrier-protein described in moDCs is the P-selectin glycoprotein ligand-1 (PSGL-1) (123), a mucinlike glycoprotein, present in the microvilli of most leukocytes (130, 131) (Figure 2, "Cell adhesion" feature). In DCs, sLe ${ }^{\mathrm{x}}$ decorating PSGL-1 is the solely ligand for P-selectin, with significant less affinity toward L-selectin and being indifferent for E-selectin binding (126).

Nevertheless, sialic acids also participate in the chemokine receptor-mediated firm arrest, as well as in $\beta 1$ integrins function (132-134). There is also evidence concerning the chemokinemediated migration to the lymph nodes. It was recently reported that ST8Sia-4-dependent polysialylation of neuropilin-2 seems to be relevant for chemokine-driven migration toward lymph nodes (135). Other report claims that ST3Gal-IV is not relevant for chemokine-dependent DC homing, in the mouse model (120), but, interestingly, our team's preliminary studies using ST6GalI-deficient mice have shown impaired DC migration toward draining lymph nodes, suggesting a previously unknown role for $\alpha 2,6$-sialylated $N$-glycans in DC homing.

Dendritic cell mobility is a crucial step still needing to be better elucidated. Most of the clinically efficacy of DC immunotherapy relies on the migration ability of these cells. In ex vivo generated DC vaccines, it is estimated that only $1-2 \%$ of total administered DCs reach secondary lymphatic organs (136). Therefore the majority of ex vivo generated DCs are inefficient because they do not meet $\mathrm{T}$ cells. Thus, understanding $\mathrm{DC}$ migration should be regarded as important to find means to improve DC immunotherapy.

\section{SIALIC ACID IN DENDRITIC CELL-T CELL INTERACTIONS}

The ultimate function of DC immunobiology is the DC-T cell interaction, whereupon DCs present the uptaken, processed antigens to $\mathrm{T}$ cells, thus eliciting a specific, long-lasting immune response. Since immunological synapses between these two cells involve glycoprotein receptor-mediated process, it is, thusly, potentially influenced by sialic acid.

Dendritic cells' sialic acid-containing glycans have been shown to negatively influence $\mathrm{T}$ cell priming, most likely by interference on MHC-mediated antigen presentation and co-stimulation (137, 138). In line with these findings, sialidase-treated moDCs were able to prime $\mathrm{T}$ cells and induce proliferation more efficiently than fully sialylated moDCs $(3,111)$. This effect could be attributable to the increased maturation by sialidase-treated moDCs (3). However, one should not discard a synergistic effect with enhanced protein-protein interaction due to the absence of the negatively charged sialic acid (137), leading to enhanced inter cellular interactions. The verified upregulation of a set of pro-inflammatory, Th1 profile-inducing cytokine expression (viz., IL- $1 \alpha,-6,-12$, and TNF$\alpha$ ) in sialidase-treated moDCs (with subsequent IFN- $\gamma$ secretion) could also account for the observed increased priming.

Reinforcing these results, others have observed that endogenous sialidase activity also promotes cytokine production by moDCs and this has been attributable to the action of Neu3 upregulation during moDC differentiation (62). Interestingly, tolerogenic, immature moDCs present high sialic acid content, as well as regulatory T cells. Thus it has been hypothesized that, host-tolerance induction by DCs could be a Siglec-mediated process (93).

Taken together, this evidence reminds that DC sialylation has implications in the $\mathrm{T}$ cell interaction and it is likely to twist the immunogenic/tolerogenic balance. Thus sialylation should be considered to fine tune DC-based therapy either pathologytreating or tolerance-inducing.

\section{DENDRITIC CELL GLYCAN RECOGNITION OF TUMORS}

Dendritic cells functions also include specific identification of tumor cells and presentation of tumor antigens to $\mathrm{T}$ cells. One of the mechanisms for tumor cells recognition is through the binding of cells surface receptors to tumor-specific antigen (TSA), with an almost exclusive tumor expression and tumor-associated antigens (TAAs), normally expressed on the cells but of aberrant expression on tumor cells (139). Upon recognition, these antigens normally elicit a maturation response on DCs but the immune potency depends on many factors, including the antigen. Tumors have, however, several evasion strategies from immune responses, achieving this by creating a tolerance-inducing microenvironment, secretion of inhibitory factors, and activation of immunosuppressant intracellular pathways in the immune cells (140-142). DCs present certain flaws in their antigen-presenting strategy that tumor cells take advantage of in order to create defective $\mathrm{T}$ cell responses, thus creating problems in generating effective anti-tumoral solutions $(142,143)$.

Aberrant glycosylation is a hallmark of cancer cells and aberrant glycosylated proteins can be shed into the body fluids of the patients (serum, urine, pleural effusions, etc.). This altered glycosylation pattern in tumor cells includes either a loss or a gain of expression of certain glycan structures, the appearance of truncated structures, as well as of novel structures. Upregulation and/or downregulation of specific glycosyltransferases is often responsible for these changes. Tumor-associated carbohydrate (TAC) structures allow tumor cells to invade and metastasize 

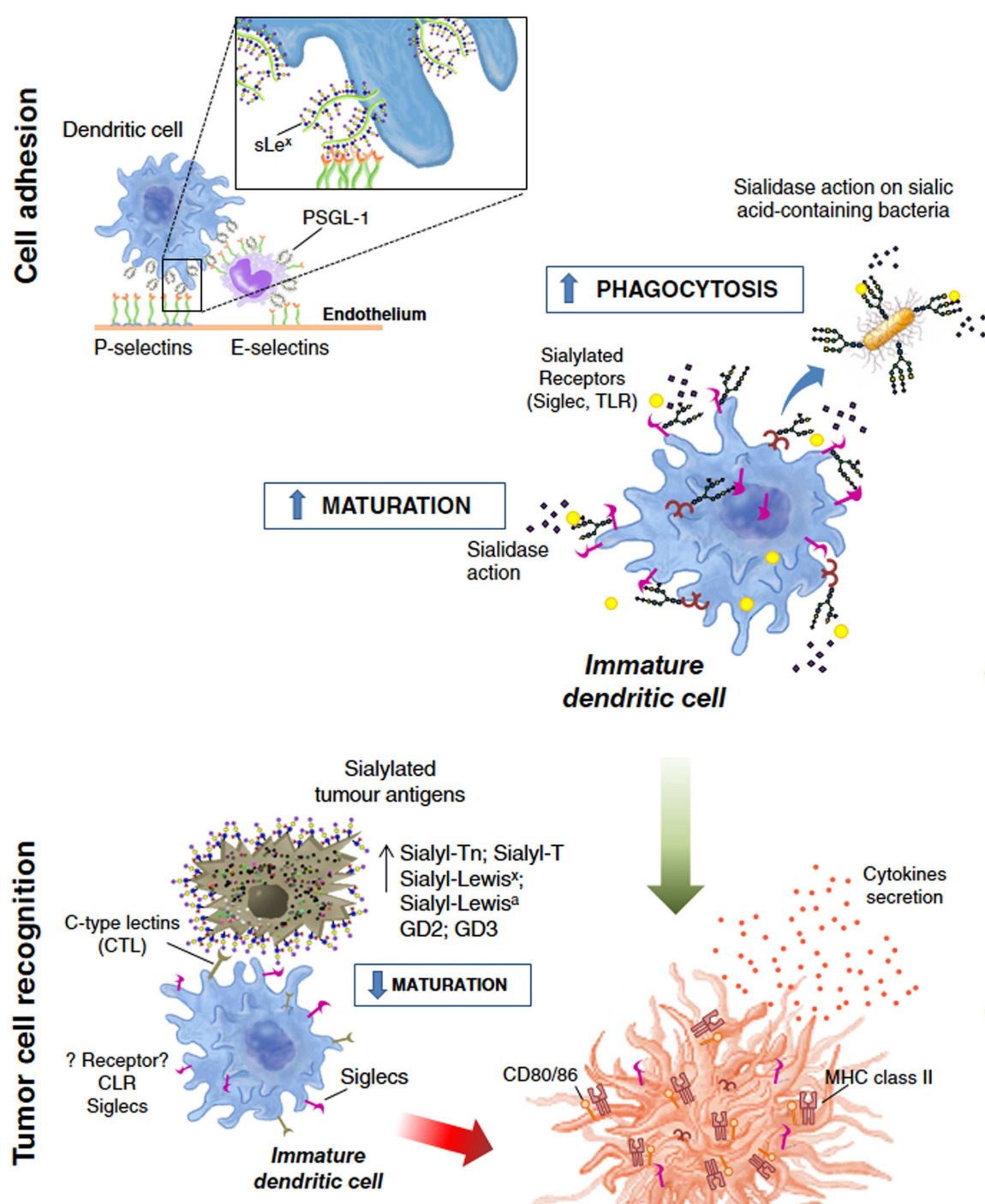

$\therefore \therefore$

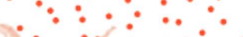

dendritic cell

FIGURE 2 | General overview of the dendritic cell functions modulated by sialylation. Sialic acid-containing glycans actively participate and modulate processes like: cell adhesion during migration and homing; or in "de facto" immune processes such as tumor cell recognition and microbial recognition, overall modulating the immune response/tolerance balance. or to evade the immune system. Immature and/or tolerogenic DCs can migrate to the rapidly growing tumor microenvironment, thus eliciting immune tolerance in several ways, such as $\mathrm{T}$ cell deletion, anergy, and $\mathrm{T}_{\text {reg }}$ activation (142-145). The tolerogenic profile depends on the DCs recognition and binding to TAC. However, how DCs recognize the tumor cells and in particular the TAC are not fully disclosed. The few available studies point, so far, to the CLRs, MGL-1, and DC-SIGN receptors as being relevant in tumor recognition and undesired tolerance induction $(37,146)$ : the former is highly expressed in immature, tolerogenic DCs, and shown to interact with the tumor-associated Tn antigen-bearing forms of MUC1 (147); the latter is also expressed by immature DCs and recognizes $\operatorname{Le}^{\mathrm{x}}$ and Lewis $\mathrm{Y}\left(\mathrm{Le}^{\mathrm{y}}\right)$ glycoantigens in a carcinoembryonic antigencontext expressed in colorectal carcinoma. Besides these receptors, the observed involvement of DCs' Siglecs (such as Siglec-3 and -9) could help justifying the frequent tolerance-induction mechanisms: by recognizing overexpressed sialylated antigens at the tumor microenvironment (e.g., sialyl $\mathrm{T}$ and sLe ${ }^{\mathrm{a}}$ expressed on mucins), these receptors could send inhibitory intracellular 
signals from their ITIM motifs thus preventing DCs from differentiating (by inducing apoptosis of their precursors) or maturating, keeping them in a tolerance-inducing state with concomitant upregulated anti-inflammatory cytokine expression, downregulated pro-inflammatory cytokine expression, and reduced antigen-presenting capability (148-150).

It is now evident that TAC and in particular, sialic acid expression influences tumor progression. DCs become tolerogenic after recognition of TAC (including glycan-bearing/glycosylated TAC), favoring tumor progression and being generally associated with bad prognosis. The collected evidence regarding the glycan influence on anti-carcinogenic immune processes should be, therefore, seriously considered whenever DC-based immunotherapies against specific malignancies are available.

\section{CONCLUDING REMARKS}

The weight of glycosylation and, in particular, sialic acid in biological processes is being increasingly acknowledged. Being at the terminal position of many glycans, it plays an essential role in modulating many of the DC functions. In human DCs, the majority of studies to date have focused on moDCs and only scattered and very scarce data was reported regarding other subsets. It would be extremely important to study these and other immune mechanisms from the newly identified subsets' perspective and to complement those studies using mouse DCs other than the traditionally (myeloid) BMDCs. Being known that different subsets of DCs have different functions/affinities toward different pathogens/tissues (and elicit different responses) it should not come as a surprise that different subsets could express different glycans and glycan-recognizing receptors, having thus different underlying mechanisms and eliciting different immune responses. The discovery and accessibility of new, faster, and more precise glycobiology-related techniques may allow a better understanding of the role of sialylation and glycosylation in DCs. The problem that poses glycobiologists, and immunologists in particular, is trying to add a new perspective and knowledge, in the same magnitude, to the amount of knowledge that proteomics and genetics have gathered the last 30 or 40 years, in a short amount of time. That premise is getting growingly important every time a relevant role for glyco-based phenomenon is identified. Our hope, with this review is that we contributed a little bit more to put the spotlight on Glycoimmunology and encourage further investigations on this subject.

\section{ACKNOWLEDGMENTS}

This work was supported by the Portuguese Foundation for Science and Technology (FCT) - PTDC/SAU-MII/67561/2006 and CEDOC (Paula A. Videira) and SFRH/BD/61204/2009 (Hélio J. Crespo). FCT is co-financed by European Social Fund (ESF) under Human Potential Operation Program (POPH) from National Strategic Reference Framework (NSRF).

\section{REFERENCES}

1. Collin M, Bigley V, Haniffa M, Hambleton S. Human dendritic cell deficiency: the missing ID? Nat Rev Immunol (2011) 11:575-83. doi:10.1038/nri3046

2. Bax M, Garcia-Vallejo JJ, Jang-Lee J, North SJ, Gilmartin TJ, Hernandez G, et al. Dendritic cell maturation results in pronounced changes in glycan expression affecting recognition by siglecs and galectins. J Immunol (2007) 179:8216-24.
3. Crespo HJ, Cabral MG, Teixeira AV, Lau JTY, Trindade H, Videira PA. Effect of sialic acid loss on dendritic cell maturation. Immunology (2009) 128:e621-31. doi:10.1111/j.1365-2567.2009.03047.x

4. Videira PA, Amado IF, Crespo HJ, Alguero MC, Dall'Olio F, Cabral MG, et al. Surface alpha 2-3- and alpha 2-6-sialylation of human monocytes and derived dendritic cells and its influence on endocytosis. Glycoconj J (2008) 25:259-68. doi:10.1007/s10719-007-9092-6

5. Harwood NE, Batista FD. Antigen presentation to B cells. F1000 Biol Rep (2010) 2:87. doi:10.3410/B2-87

6. Palucka K, Banchereau J. How dendritic cells and microbes interact to elicit or subvert protective immune responses. Curr Opin Immunol (2002) 14:420-31. doi:10.1016/S0952-7915(02)00365-5

7. Qi H, Egen JG, Huang AY, Germain RN. Extrafollicular activation of lymph node B cells by antigen-bearing dendritic cells. Science (2006) 312:1672-6. doi:10.1126/science.1125703

8. Shortman K, Naik SH. Steady-state and inflammatory dendritic-cell development. Nat Rev Immunol (2007) 7:19-30. doi:10.1038/nri1996

9. D'Amico A, Wu L. The early progenitors of mouse dendritic cells and plasmacytoid predendritic cells are within the bone marrow hemopoietic precursors expressing Flt3. J Exp Med (2003) 198:293-303. doi:10.1084/jem.20030107

10. Ishikawa F, Niiro H, Iino T, Yoshida S, Saito N, Onohara S, et al. The developmental program of human dendritic cells is operated independently of conventional myeloid and lymphoid pathways. Blood (2007) 110:3591-660. doi:10.1182/blood-2007-02-071613

11. Manz MG, Traver D, Miyamoto T, Weissman IL, Akashi K. Dendritic cell potentials of early lymphoid and myeloid progenitors. Blood (2001) 97:3333-41. doi:10.1182/blood.V97.11.3333

12. Shigematsu H, Reizis B, Iwasaki H, Mizuno S, Hu D, Traver D, et al. Plasmacytoid dendritic cells activate lymphoid-specific genetic programs irrespective of their cellular origin. Immunity (2004) 21:43-53. doi:10.1016/j.immuni.2004. 06.011

13. Singh P, Hoggatt J, Hu P, Speth JM, Fukuda S, Breyer RM, et al. Blockade of prostaglandin E2 signaling through EP1 and EP3 receptors attenuates Flt3Ldependent dendritic cell development from hematopoietic progenitor cells. Blood (2012) 119:1671-82. doi:10.1182/blood-2011-03-342428

14. Watowich SS, Liu YJ. Mechanisms regulating dendritic cell specification and development. Immunol Rev (2010) 238:76-92. doi:10.1111/j.1600-065X.2010. 00949.x

15. Schraml BU, van Blijswijk J, Zelenay S, Whitney PG, Filby A, Acton SE, et al. Genetic tracing via DNGR-1 expression history defines dendritic cells as a hematopoietic lineage. Cell (2013) 154:843-58. doi:10.1016/j.cell.2013.07.014

16. Grouard G, Rissoan MC, Filgueira L, Durand I, Banchereau J, Liu YJ. The enigmatic plasmacytoid T cells develop into dendritic cells with interleukin (IL)-3 and CD40-ligand. J Exp Med (1997) 185:1101-11. doi:10.1084/jem.185.6.1101

17. O'Keeffe M, Hochrein H, Vremec D, Caminschi I, Miller JL, Anders EM, et al. Mouse plasmacytoid cells: long-lived cells, heterogeneous in surface phenotype and function, that differentiate into CD8 $(+)$ dendritic cells only after microbial stimulus. J Exp Med (2002) 196:1307-19. doi:10.1084/jem.20021031

18. Segura E, Amigorena S. Inflammatory dendritic cells in mice and humans. Trends Immunol (2013) 34(9):440-5. doi:10.1016/j.it.2013.06.001

19. Sallusto F, Cella M, Danieli C, Lanzavecchia A. Dendritic cells use macropinocytosis and the mannose receptor to concentrate macromolecules in the major histocompatibility complex class II compartment: downregulation by cytokines and bacterial products. J Exp Med (1995) 182:389-400. doi:10.1084/ jem.182.2.389

20. Norbury CC. Drinking a lot is good for dendritic cells. Immunology (2006) 117:443-51. doi:10.1111/j.1365-2567.2006.02335.x

21. Wilson NS, El-Sukkari D, Belz GT, Smith CM, Steptoe RJ, Heath WR, et al. Most lymphoid organ dendritic cell types are phenotypically and functionally immature. Blood (2003) 102:2187-94. doi:10.1182/blood-2003-02-0513

22. Kramer A, Bekeschus S, Broker BM, Schleibinger H, Razavi B, Assadian O. Maintaining health by balancing microbial exposure and prevention of infection: the hygiene hypothesis versus the hypothesis of early immune challenge. J Hosp Infect (2013) 83(Suppl 1):S29-34. doi:10.1016/S01956701(13)60007-9

23. Rook GA. Review series on helminths, immune modulation and the hygiene hypothesis: the broader implications of the hygiene hypothesis. Immunology (2009) 126:3-11. doi:10.1111/j.1365-2567.2008.03007.x 
24. Rook GA. 99th Dahlem conference on infection, inflammation and chronic inflammatory disorders: darwinian medicine and the "hygiene" or "old friends" hypothesis. Clin Exp Immunol (2010) 160:70-9. doi:10.1111/j.1365-2249.2010. 04133.x

25. Thomas R, Lipsky PE. Human peripheral blood dendritic cell subsets. Isolation and characterization of precursor and mature antigen-presenting cells. J Immunol (1994) 153:4016-28.

26. Sallusto F, Lanzavecchia A. Efficient presentation of soluble antigen by cultured human dendritic cells is maintained by granulocyte/macrophage colony-stimulating factor plus interleukin 4 and downregulated by tumor necrosis factor alpha. J Exp Med (1994) 179:1109-18. doi:10.1084/jem.179. 4.1109

27. Bonasio R, von Andrian UH. Generation, migration and function of circulating dendritic cells. Curr Opin Immunol (2006) 18:503-11. doi:10.1016/j.coi. 2006.05.011

28. Forster R, Braun A, Worbs T. Lymph node homing of T cells and dendritic cells via afferent lymphatics. Trends Immunol (2012) 33:271-80. doi:10.1016/j. it.2012.02.007

29. von Andrian UH, Mempel TR. Homing and cellular traffic in lymph nodes. Nat Rev Immunol (2003) 3:867-78. doi:10.1038/nri1222

30. Netea MG, van der Graaf C, Van der Meer JW, Kullberg BJ. Toll-like receptors and the host defense against microbial pathogens: bringing specificity to the innate-immune system. J Leukoc Biol (2004) 75:749-55. doi:10.1189/jlb. 1103543

31. Schnare M, Holt AC, Takeda K, Akira S, Medzhitov R. Recognition of CpG DNA is mediated by signaling pathways dependent on the adaptor protein MyD88. Curr Biol (2000) 10:1139-42. doi:10.1016/S0960-9822(00)00700-4

32. Dzopalic T, Rajkovic I, Dragicevic A, Colic M. The response of human dendritic cells to co-ligation of pattern-recognition receptors. Immunol Res (2012) 52:20-33. doi:10.1007/s12026-012-8279-5

33. Takeda K, Kaisho T, Akira S. Toll-like receptors. Annu Rev Immunol (2003) 21:335-76. doi:10.1146/annurev.immunol.21.120601.141126

34. Zelensky AN, Gready JE. The C-type lectin-like domain superfamily. FEBS J (2005) 272:6179-217. doi:10.1111/j.1742-4658.2005.05031.x

35. van Kooyk Y, Rabinovich GA. Protein-glycan interactions in the control of innate and adaptive immune responses. Nat Immunol (2008) 9:593-601. doi:10.1038/ni.f.203

36. Figdor CG, de Vries IJ, Lesterhuis WJ, Melief CJ. Dendritic cell immunotherapy: mapping the way. Nat Med (2004) 10:475-80. doi:10.1038/nm1039

37. van Gisbergen KP, Aarnoudse CA, Meijer GA, Geijtenbeek TB, van Kooyk Y. Dendritic cells recognize tumor-specific glycosylation of carcinoembryonic antigen on colorectal cancer cells through dendritic cell-specific intercellular adhesion molecule-3-grabbing nonintegrin. Cancer Res (2005) 65:5935-44. doi:10.1158/0008-5472.CAN-04-4140

38. van Kooyk Y. C-type lectins on dendritic cells: key modulators for the induction of immune responses. Biochem Soc Trans (2008) 36:1478-81. doi:10.1042/ BST0361478

39. van Kooyk Y, Engering A, Lekkerkerker AN, Ludwig IS, Geijtenbeek TB. Pathogens use carbohydrates to escape immunity induced by dendritic cells. Curr Opin Immunol (2004) 16:488-93. doi:10.1016/j.coi.2004.05.010

40. Crocker PR. Siglecs in innate immunity. Curr Opin Pharmacol (2005) 5:431-7. doi:10.1016/j.coph.2005.03.003

41. Crocker PR, Paulson JC, Varki A. Siglecs and their roles in the immune system. Nat Rev Immunol (2007) 7:255-66. doi:10.1038/nri2056

42. Kawasaki N, Vela JL, Nycholat CM, Rademacher C, Khurana A, van Rooijen $\mathrm{N}$, et al. Targeted delivery of lipid antigen to macrophages via the CD169/sialoadhesin endocytic pathway induces robust invariant natural killer T cell activation. Proc Natl Acad Sci U S A (2013) 110:7826-31. doi:10.1073/ pnas. 1219888110

43. Lock K, Zhang J, Lu J, Lee SH, Crocker PR. Expression of CD33-related siglecs on human mononuclear phagocytes, monocyte-derived dendritic cells and plasmacytoid dendritic cells. Immunobiology (2004) 209:199-207. doi:10.1016/ j.imbio.2004.04.007

44. Ben Nasr A, Haithcoat J, Masterson JE, Gunn JS, Eaves-Pyles T, Klimpel GR. Critical role for serum opsonins and complement receptors CR3 (CD11b/CD18) and CR4 (CD11c/CD18) in phagocytosis of Francisella tularensis by human dendritic cells (DC): uptake of Francisella leads to activation of immature DC and intracellular survival of the bacteria. J Leukoc Biol (2006) 80:774-86 . doi:10.1189/jlb.1205755
45. Sedlik C, Orbach D, Veron P, Schweighoffer E, Colucci F, Gamberale R, et al. A critical role for Syk protein tyrosine kinase in Fc receptor-mediated antigen presentation and induction of dendritic cell maturation. J Immunol (2003) 170:846-52.

46. Caminschi I, Shortman K. Boosting antibody responses by targeting antigens to dendritic cells. Trends Immunol (2012) 33:71-7. doi:10.1016/j.it.2011.10.007

47. Matos I, Mizenina O, Lubkin A, Steinman RM, Idoyaga J. Targeting antigens to dendritic cells in vivo induces protective immunity. PLoS One (2013) 8:e67453. doi:10.1371/journal.pone.0067453

48. Mintern JD, Percival C, Kamphuis MM, Chin WJ, Caruso F, Johnston AP. Targeting dendritic cells: the role of specific receptors in the internalization of polymer capsules. Adv Healthc Mater (2013) 2:940-4. doi:10.1002/adhm. 201200441

49. Phanse Y, Carrillo-Conde BR, Ramer-Tait AE, Roychoudhury R, Pohl NLB, Narasimhan B, et al. Functionalization of polyanhydride microparticles with di-mannose influences uptake by and intracellular fate within dendritic cells. Acta Biomater (2013) 9, 8902-9. doi:10.1016/j.actbio.2013.06.024

50. Yao Y, Chen L, Wei W, Deng X, Ma L, Hao S. Tumor cell-derived exosometargeted dendritic cells stimulate stronger CD8+ CTL responses and antitumor immunities. Biochem Biophys Res Commun (2013) 436:60-5. doi:10.1016/ j.bbrc.2013.05.058

51. Cao J, Jin Y, Li W, Zhang B, He Y, Liu H, et al. DNA vaccines targeting the encoded antigens to dendritic cells induce potent antitumor immunity in mice. BMC Immunol (2013) 14:39. doi:10.1186/1471-2172-14-39

52. Liechtenstein T, Perez-Janices N, Bricogne C, Lanna A, Dufait I, Goyvaerts $\mathrm{C}$, et al. Immune modulation by genetic modification of dendritic cells with lentiviral vectors. Virus Res (2013) 176:1-15. doi:10.1016/j.virusres.2013. 05.007

53. Banerjee DK. N-glycans in cell survival and death: cross-talk between glycosyltransferases. Biochim Biophys Acta (2012) 1820:1338-46. doi:10.1016/j.bbagen. 2012.01.013

54. Cabral MG, Piteira AR, Silva Z, Ligeiro D, Brossmer R, Videira PA. Human dendritic cells contain cell surface sialyltransferase activity. Immunol Lett (2010) 131:89-96. doi:10.1016/j.imlet.2010.02.009

55 . Hennet T. Diseases of glycosylation beyond classical congenital disorders of glycosylation. Biochim Biophys Acta (2012) 1820:1306-17. doi:10.1016/j.bbagen. 2012.02.001

56. Rosnoblet C, Peanne R, Legrand D, Foulquier F. Glycosylation disorders of membrane trafficking. Glycoconj J (2013) 30:23-31. doi:10.1007/s10719-0129389-y

57. Varki NM, Varki A. Diversity in cell surface sialic acid presentations: implications for biology and disease. Lab Invest (2007) 87:851-7. doi:10.1038/ labinvest. 3700656

58. Sonnenburg JL, Altheide TK, Varki A. A uniquely human consequence of domain-specific functional adaptation in a sialic acid-binding receptor. Glycobiology (2004) 14:339-46. doi:10.1093/glycob/cwh039

59. Jones MB, Nasirikenari M, Feng L, Migliore MT, Choi KS, Kazim L, et al. Role for hepatic and circulatory ST6Gal-1 sialyltransferase in regulating myelopoiesis. J Biol Chem (2010) 285:25009-17. doi:10.1074/jbc.M110.104406

60. Harduin-Lepers A, Vallejo-Ruiz V, Krzewinski-Recchi MA, Samyn-Petit B, Julien S, Delannoy P. The human sialyltransferase family. Biochimie (2001) 83:727-37. doi:10.1016/S0300-9084(01)01301-3

61. Miyagi T, Takahashi K, Hata K, Shiozaki K, Yamaguchi K. Sialidase significance for cancer progression. GlycoconjJ (2012) 29:567-77. doi:10.1007/s10719-0129394- 1

62. Stamatos NM, Carubelli I, van de Vlekkert D, Bonten EJ, Papini N, Feng C, et al. LPS-induced cytokine production in human dendritic cells is regulated by sialidase activity. J Leukoc Biol (2010) 88:1227-39. doi:10.1189/jlb.1209776

63. Varki A, Gagneux P. Multifarious roles of sialic acids in immunity. Ann NYAcad Sci (2012) 1253:16-36. doi:10.1111/j.1749-6632.2012.06517.x

64. Jamieson JC, McCaffrey G, Harder PG. Sialyltransferase: a novel acute-phase reactant. Comp Biochem Physiol B (1993) 105:29-33.

65. Jamieson JC, Lammers G, Janzen R, Woloski BM. The acute phase response to inflammation: the role of monokines in changes in liver glycoproteins and enzymes of glycoprotein metabolism. Comp Biochem Physiol B (1987) 87:11-5.

66. Kaplan HA, Woloski BM, Hellman M, Jamieson JC. Studies on the effect of inflammation on rat liver and serum sialyltransferase. Evidence that inflammation causes release of Gal beta 1 leads to $4 \mathrm{GlcNAc}$ alpha 2 leads to 6 sialyltransferase from liver. J Biol Chem (1983) 258:11505-9. 
67. Yasukawa Z, Sato C, Kitajima K. Inflammation-dependent changes in alpha2,3-, alpha2,6-, and alpha2,8-sialic acid glycotopes on serum glycoproteins in mice. Glycobiology (2005) 15:827-37. doi:10.1093/glycob/cwi068

68. Zhuo Y, Bellis SL. Emerging role of alpha2,6-sialic acid as a negative regulator of galectin binding and function. J Biol Chem (2011) 286:5935-41. doi:10.1074/jbc.R110.191429

69. Erbacher A, Gieseke F, Handgretinger R, Müller I. Dendritic cells: functional aspects of glycosylation and lectins. Hum Immunol (2009) 70:308-12. doi:10.1016/j.humimm.2009.02.005

70. Hsu DK, Yang RY, Liu FT. Galectins in apoptosis. Methods Enzymol (2006) 417:256-73. doi:10.1016/S0076-6879(06)17018-4

71. Hughes RC. Galectins as modulators of cell adhesion. Biochimie (2001) 83:667-76. doi:10.1016/S0300-9084(01)01289-5

72. Leffler H, Carlsson S, Hedlund M, Qian Y, Poirier F. Introduction to galectins. Glycoconj J (2004) 19:433-40. doi:10.1023/B:GLYC.0000014072.34840.04

73. Nakahara S, Raz A. On the role of galectins in signal transduction. Methods Enzymol (2006) 417:273-89. doi:10.1016/S0076-6879(06)17019-6

74. Freire-de-Lima L, Oliveira IA, Neves JL, Penha LL, Alisson-Silva F, Dias WB, et al. Sialic acid: a sweet swing between mammalian host and Trypanosoma cruzi. Front Immunol (2012) 3:356. doi:10.3389/fimmu.2012.00356

75. Paris G, Ratier L, Amaya MF, Nguyen T, Alzari PM, Frasch AC. A sialidase mutant displaying trans-sialidase activity. J Mol Biol (2005) 345:923-34. doi:10.1016/j.jmb.2004.09.031

76. Sperandio M. Selectins and glycosyltransferases in leukocyte rolling in vivo. FEBS J (2006) 273:4377-89. doi:10.1111/j.1742-4658.2006.05437.x

77. Pillai S, Netravali IA, Cariappa A, Mattoo H. Siglecs and immune regulation. Annu Rev Immunol (2012) 30:357-92. doi:10.1146/annurev-immunol020711-075018

78. Crocker PR, Redelinghuys P. Siglecs as positive and negative regulators of the immune system. Biochem Soc Trans (2008) 36:1467-71. doi:10.1042/ BST0361467

79. Liu Y, Chen GY, Zheng P. CD24-Siglec G/10 discriminates danger- from pathogen-associated molecular patterns. Trends Immunol (2009) 30:557-61. doi:10.1016/j.it.2009.09.006

80. Hennet T, Chui D, Paulson JC, Marth JD. Immune regulation by the ST6Gal sialyltransferase. Proc Natl Acad Sci U S A (1998) 95:4504-9. doi:10.1073/pnas. 95.8.4504

81. Moody AM, North SJ, Reinhold B, Van Dyken SJ, Rogers ME, Panico M, et al. Sialic acid capping of CD8beta core 1-O-glycans controls thymocyte-major histocompatibility complex class I interaction. J Biol Chem (2003) 278:7240-6. doi:10.1074/jbc.M210468200

82. Priatel JJ, Chui D, Hiraoka N, Simmons CJ, Richardson KB, Page DM, et al. The ST3Gal-I sialyltransferase controls CD8+ T lymphocyte homeostasis by modulating O-glycan biosynthesis. Immunity (2000) 12:273-83. doi:10.1016/S1074-7613(00)80180-6

83. Powell LD, Sgroi D, Sjoberg ER, Stamenkovic I, Varki A. Natural ligands of the B cell adhesion molecule CD22 beta carry N-linked oligosaccharides with alpha2,6-linked sialic acids that are required for recognition. J Biol Chem (1993) 268:7019-27.

84. Ghosh S, Bandulet C, Nitschke L. Regulation of B cell development and B cell signalling by CD22 and its ligands alpha2,6-linked sialic acids. Int Immunol (2006) 18:603-11. doi:10.1093/intimm/dxh402

85. Nasirikenari M, Chandrasekaran EV, Matta KL, Segal BH, Bogner PN, Lugade AA, et al. Altered eosinophil profile in mice with ST6Gal-1 deficiency: an additional role for ST6Gal-1 generated by the P1 promoter in regulating allergic inflammation. J Leukoc Biol (2010) 87:457-66. doi:10.1189/jlb.1108704

86. Nasirikenari M, Segal BH, Ostberg JR, Urbasic A, Lau JT. Altered granulopoietic profile and exaggerated acute neutrophilic inflammation in mice with targeted deficiency in the sialyltransferase ST6Gal I. Blood (2006) 108:3397-405. doi:10.1182/blood-2006-04-014779

87. Steinman RM, Adams JC, Cohn ZA. Identification of a novel cell type in peripheral lymphoid organs of mice. IV. Identification and distribution in mouse spleen. J Exp Med (1975) 141:804-20.

88. Steinman RM, Cohn ZA. Identification of a novel cell type in peripheral lymphoid organs of mice. I. Morphology, quantitation, tissue distribution. J Exp Med (1973) 137:1142-62. doi:10.1084/jem.137.5.1142

89. Steinman RM, Cohn ZA. Identification of a novel cell type in peripheral lymphoid organs of mice. II. Functional properties in vitro. J Exp Med (1974) 139:380-97. doi:10.1084/jem.139.2.380
90. Steinman RM, Lustig DS, Cohn ZA. Identification of a novel cell type in peripheral lymphoid organs of mice. III. Functional properties in vivo. J Exp Med (1974) 139:1431-45. doi:10.1084/jem.139.6.1431

91. Steinman RM, Witmer MD. Lymphoid dendritic cells are potent stimulators of the primary mixed leukocyte reaction in mice. Proc Natl Acad Sci U S A (1978) 75:5132-6. doi:10.1073/pnas.75.10.5132

92. Lutz MB, Kukutsch N, Ogilvie AL, Rossner S, Koch F, Romani N, et al. An advanced culture method for generating large quantities of highly pure dendritic cells from mouse bone marrow. J Immunol Methods (1999) 223:77-92. doi:10.1016/S0022-1759(98)00204-X

93. Jenner J, Kerst G, Handgretinger R, Muller I. Increased alpha2,6-sialylation of surface proteins on tolerogenic, immature dendritic cells and regulatory $\mathrm{T}$ cells. Exp Hematol (2006) 34:1212-8. doi:10.1016/j.exphem.2006.04.016

94. Trottein F, Schaffer L, Ivanov S, Paget C, Vendeville C, Cazet A, et al. Glycosyltransferase and sulfotransferase gene expression profiles in human monocytes, dendritic cells and macrophages. Glycoconj J (2009) 26:1259-74. doi:10.1007/s10719-009-9244-y

95. Hemont C, Neel A, Heslan M, Braudeau C, Josien R. Human blood mDC subsets exhibit distinct TLR repertoire and responsiveness. J Leukoc Biol (2013) 93:599-609. doi:10.1189/jlb.0912452

96. Crocker PR, McMillan SJ, Richards HE. CD33-related siglecs as potential modulators of inflammatory responses. Ann N Y Acad Sci (2012) 1253:102-11. doi:10.1111/j.1749-6632.2011.06449.x

97. Freeman SD, Kelm S, Barber EK, Crocker PR. Characterization of CD33 as a new member of the sialoadhesin family of cellular interaction molecules. Blood (1995) 85:2005-12.

98. Crocker PR. Siglecs: sialic-acid-binding immunoglobulin-like lectins in cellcell interactions and signalling. Curr Opin Struct Biol (2002) 12:609-15. doi:10.1016/S0959-440X(02)00375-5

99. Santos L, Draves KE, Boton M, Grewal PK, Marth JD, Clark EA. Dendritic celldependent inhibition of B cell proliferation requires CD22. J Immunol (2008) 180:4561-9.

100. Chen GY, Tang J, Zheng P, Liu Y. CD24 and Siglec-10 selectively repress tissue damage-induced immune responses. Science (2009) 323:1722-5. doi:10.1126/ science. 1168988

101. Bax M, Kuijf ML, Heikema AP, van Rijs W, Bruijns SC, Garcia-Vallejo JJ, et al. Campylobacter jejuni lipooligosaccharides modulate dendritic cell-mediated $\mathrm{T}$ cell polarization in a sialic acid linkage-dependent manner. Infect Immun (2011) 79:2681-9. doi:10.1128/IAI.00009-11

102. Avril T, Attrill H, Zhang J, Raper A, Crocker PR. Negative regulation of leucocyte functions by CD33-related siglecs. Biochem Soc Trans (2006) 34:1024-7. doi:10.1042/BST0341024

103. Carlin AF, Lewis AL, Varki A, Nizet V. Group B streptococcal capsular sialic acids interact with siglecs (immunoglobulin-like lectins) on human leukocytes. J Bacteriol (2007) 189:1231-7. doi:10.1128/JB.01155-06

104. Jones C, Virji M, Crocker PR. Recognition of sialylated meningococcal lipopolysaccharide by siglecs expressed on myeloid cells leads to enhanced bacterial uptake. Mol Microbiol (2003) 49:1213-25. doi:10.1046/j.1365-2958. 2003.03634.x

105. Khatua B, Ghoshal A, Bhattacharya K, Mandal C, Saha B, Crocker PR. Sialic acids acquired by Pseudomonas aeruginosa are involved in reduced complement deposition and siglec mediated host-cell recognition. FEBS Lett (2010) 584:555-61. doi:10.1016/j.febslet.2009.11.087

106. Biedermann B, Gil D, Bowen DT, Crocker PR. Analysis of the CD33related siglec family reveals that Siglec- 9 is an endocytic receptor expressed on subsets of acute myeloid leukemia cells and absent from normal hematopoietic progenitors. Leuk Res (2007) 31:211-20. doi:10.1016/j.leukres. 2006.05.026

107. Izquierdo-Useros N, Lorizate M, Puertas MC, Rodriguez-Plata MT, Zangger N, Erikson E, et al. Siglec-1 is a novel dendritic cell receptor that mediates HIV-1 trans-infection through recognition of viral membrane gangliosides. PLoS Biol (2012) 10:e1001448. doi:10.1371/journal.pbio.1001448

108. Severi E, Hood DW, Thomas GH. Sialic acid utilization by bacterial pathogens. Microbiology (2007) 153:2817-22. doi:10.1099/mic.0.2007/009480-0

109. Lim JP, Gleeson PA. Macropinocytosis: an endocytic pathway for internalising large gulps. Immunol Cell Biol (2011) 89:836-43. doi:10.1038/icb.2011.20

110. Nayak JV, Hokey DA, Larregina A, He Y, Salter RD, Watkins SC, et al. Phagocytosis induces lysosome remodeling and regulated presentation of particulate antigens by activated dendritic cells. J Immunol (2006) 177:8493-503. 
111. Cabral MG, Silva Z, Ligeiro D, Seixas E, Crespo H, Carrascal MA, et al. The phagocytic capacity and immunological potency of human dendritic cells is improved by $\alpha 2,6$-sialic acid deficiency. Immunology (2013) 138:235-45. doi:10.1111/imm.12025

112. Garrett WS, Chen LM, Kroschewski R, Ebersold M, Turley S, Trombetta S, et al. Developmental control of endocytosis in dendritic cells by Cdc42. Cell (2000) 102:325-34. doi:10.1016/S0092-8674(00)00038-6

113. Platt CD, Ma JK, Chalouni C, Ebersold M, Bou-Reslan H, Carano RA, et al. Mature dendritic cells use endocytic receptors to capture and present antigens. Proc Natl Acad Sci U S A (2010) 107:4287-92. doi:10.1073/pnas. 0910609107

114. Austyn JM. New insights into the mobilization and phagocytic activity of dendritic cells. J Exp Med (1996) 183:1287-92. doi:10.1084/jem.183.4.1287

115. Inaba K, Inaba M, Naito M, Steinman RM. Dendritic cell progenitors phagocytose particulates, including bacillus Calmette-Guerin organisms, and sensitize mice to mycobacterial antigens in vivo. J Exp Med (1993) 178:479-88. doi:10.1084/jem.178.2.479

116. Shurin GV, Tourkova IL, Chatta GS, Schmidt G, Wei S, Djeu JY, et al. Small rho GTPases regulate antigen presentation in dendritic cells. J Immunol (2005) 174:3394-400.

117. Amith SR, Jayanth P, Franchuk S, Finlay T, Seyrantepe V, Beyaert R, et al. Neul desialylation of sialyl alpha-2,3-linked beta-galactosyl residues of TOLL-like receptor 4 is essential for receptor activation and cellular signaling. Cell Signal (2010) 22:314-24. doi:10.1016/j.cellsig.2009.09.038

118. Seyrantepe V, Iannello A, Liang F, Kanshin E, Jayanth P, Samarani S, et al. Regulation of phagocytosis in macrophages by neuraminidase 1. J Biol Chem (2010) 285:206-15. doi:10.1074/jbc.M109.055475

119. Watanabe Y, Shiratsuchi A, Shimizu K, Takizawa T, Nakanishi Y. Stimulation of phagocytosis of influenza virus-infected cells through surface desialylation of macrophages by viral neuraminidase. Microbiol Immunol (2004) 48:875-81. doi:10.1111/j.1348-0421.2004.tb03619.x

120. Sperandio M, Gleissner CA, Ley K. Glycosylation in immune cell trafficking. Immunol Rev (2009) 230:97-113. doi:10.1111/j.1600-065X.2009.00795.x

121. McEver RP. Selectins: lectins that initiate cell adhesion under flow. Curr Opin Cell Biol (2002) 14:581-6. doi:10.1016/S0955-0674(02)00367-8

122. Patel KD, Moore KL, Nollert MU, McEver RP. Neutrophils use both shared and distinct mechanisms to adhere to selectins under static and flow conditions. J Clin Invest (1995) 96:1887-96. doi:10.1172/JCI118234

123. Julien S, Grimshaw MJ, Sutton-Smith M, Coleman J, Morris HR, Dell A, et al. Sialyl-Lewis(x) on P-selectin glycoprotein ligand-1 is regulated during differentiation and maturation of dendritic cells: a mechanism involving the glycosyltransferases C2GnT1 and ST3Gal I. J Immunol (2007) 179:5701-10.

124. Pendl GG, Robert C, Steinert M, Thanos R, Eytner R, Borges E, et al. Immature mouse dendritic cells enter inflamed tissue, a process that requires $\mathrm{E}$ - and P-selectin, but not P-selectin glycoprotein ligand 1. Blood (2002) 99:946-56. doi:10.1182/blood.V99.3.946

125. Robert C, Fuhlbrigge RC, Kieffer JD, Ayehunie S, Hynes RO, Cheng G, et al. Interaction of dendritic cells with skin endothelium: a new perspective on immunosurveillance. J Exp Med (1999) 189:627-36. doi:10.1084/jem.189. 4.627

126. Silva Z, Tong Z, Guadalupe Cabral M, Martins C, Castro R, Reis C, et al. Sialyl Lewis $(\mathrm{x})$-dependent binding of human monocyte-derived dendritic cells to selectins. Biochem Biophys Res Commun (2011) 409:459-64. doi:10.1016/j. bbrc.2011.05.026

127. Urzainqui A, Martinez del Hoyo G, Lamana A, de la Fuente H, Barreiro O, Olazabal IM, et al. Functional role of P-selectin glycoprotein ligand 1/P-selectin interaction in the generation of tolerogenic dendritic cells. J Immunol (2007) 179:7457-65.

128. Foxall C, Watson SR, Dowbenko D, Fennie C, Lasky LA, Kiso M, et al. The three members of the selectin receptor family recognize a common carbohydrate epitope, the sialyl Lewis(x) oligosaccharide. J Cell Biol (1992) 117:895-902. doi:10.1083/jcb.117.4.895

129. Marth JD, Grewal PK. Mammalian glycosylation in immunity. Nat Rev Immunol (2008) 8:874-87. doi:10.1038/nri2417

130. Kieffer JD, Fuhlbrigge RC, Armerding D, Robert C, Ferenczi K, Camphausen RT, et al. Neutrophils, monocytes, and dendritic cells express the same specialized form of PSGL-1 as do skin-homing memory T cells: cutaneous lymphocyte antigen. Biochem Biophys Res Commun (2001) 285:577-87. doi:10.1006/bbrc. 2001.5230
131. Laszik Z, Jansen PJ, Cummings RD, Tedder TF, McEver RP, Moore KL. Pselectin glycoprotein ligand-1 is broadly expressed in cells of myeloid, lymphoid, and dendritic lineage and in some nonhematopoietic cells. Blood (1996) 88:3010-21.

132. Frommhold D, Ludwig A, Bixel MG, Zarbock A, Babushkina I, Weissinger M, et al. Sialyltransferase ST3Gal-IV controls CXCR2-mediated firm leukocyte arrest during inflammation. J Exp Med (2008) 205:1435-46. doi:10.1084/jem. 20070846

133. Semel AC, Seales EC, Singhal A, Eklund EA, Colley KJ, Bellis SL. Hyposialylation of integrins stimulates the activity of myeloid fibronectin receptors. J Biol Chem (2002) 277:32830-6. doi:10.1074/jbc.M202493200

134. Woodard-Grice AV, McBrayer AC, Wakefield JK, Zhuo Y, Bellis SL. Proteolytic shedding of ST6Gal-I by BACE1 regulates the glycosylation and function of alpha4betal integrins. J Biol Chem (2008) 283:26364-73. doi:10.1074/jbc. M800836200

135. Rey-Gallardo A, Delgado-Martin C, Gerardy-Schahn R, Rodriguez-Fernandez $\mathrm{JL}$, Vega MA. Polysialic acid is required for neuropilin-2a/b-mediated control of CCL21-driven chemotaxis of mature dendritic cells, and for their migration in vivo. Glycobiology (2011) 21:655-62. doi:10.1093/glycob/cwq216

136. Ridolfi R, Riccobon A, Galassi R, Giorgetti G, Petrini M, Fiammenghi L, et al. Evaluation of in vivo labelled dendritic cell migration in cancer patients. JTransl Med (2004) 2:27. doi:10.1186/1479-5876-2-27

137. Boog CJ, Neefjes JJ, Boes J, Ploegh HL, Melief CJ. Specific immune responses restored by alteration in carbohydrate chains of surface molecules on antigenpresenting cells. Eur J Immunol (1989) 19:537-42. doi:10.1002/eji.1830190319

138. Dubsky P, Ueno H, Piqueras B, Connolly J, Banchereau J, Palucka AK. Human dendritic cell subsets for vaccination. J Clin Immunol (2005) 25:551-72. doi:10.1007/s10875-005-8216-7

139. Swann JB, Smyth MJ. Immune surveillance of tumors. J Clin Invest (2007) 117:1137-46. doi:10.1172/JCI31405

140. Banchereau J, Steinman RM. Dendritic cells and the control of immunity. Nature (1998) 392:245-52. doi:10.1038/32588

141. Condamine T, Gabrilovich DI. Molecular mechanisms regulating myeloidderived suppressor cell differentiation and function. Trends Immunol (2011) 32:19-25. doi:10.1016/j.it.2010.10.002

142. Rabinovich GA, Gabrilovich D, Sotomayor EM. Immunosuppressive strategies that are mediated by tumor cells. Annu Rev Immunol (2007) 25:267-96. doi:10.1146/annurev.immunol.25.022106.141609

143. Benencia F, Sprague L, McGinty J, Pate M, Muccioli M. Dendritic cells the tumor microenvironment and the challenges for an effective antitumor vaccination. J Biomed Biotechnol (2012) 2012:425476. doi:10.1155/2012/425476

144. Palucka K, Ueno H, Fay J, Banchereau J. Dendritic cells and immunity against cancer. J Intern Med (2011) 269:64-73. doi:10.1111/j.1365-2796.2010.02317.x

145. Strioga M, Schijns V, Powell DJ Jr, Pasukoniene V, Dobrovolskiene N, Michalek J. Dendritic cells and their role in tumor immunosurveillance. Innate Immun (2013) 19:98-111. doi:10.1177/1753425912449549

146. Saeland E, van Vliet SJ, Backstrom M, van den Berg VC, Geijtenbeek TB, Meijer GA, et al. The C-type lectin MGL expressed by dendritic cells detects glycan changes on MUC1 in colon carcinoma. Cancer Immunol Immunother (2007) 56:1225-36. doi:10.1007/s00262-006-0274-z

147. Napoletano C, Rughetti A, Agervig Tarp MP, Coleman J, Bennett EP, Picco $\mathrm{G}$, et al. Tumor-associated Tn-MUC1 glycoform is internalized through the macrophage galactose-type C-type lectin and delivered to the HLA class I and II compartments in dendritic cells. Cancer Res (2007) 67:8358-67. doi:10.1158/0008-5472.CAN-07-1035

148. Ishida A, Ohta M, Toda M, Murata T, Usui T, Akita K, et al. Mucin-induced apoptosis of monocyte-derived dendritic cells during maturation. Proteomics (2008) 8:3342-9. doi:10.1002/pmic.200800039

149. Ohta M, Ishida A, Toda M, Akita K, Inoue M, Yamashita K, et al. Immunomodulation of monocyte-derived dendritic cells through ligation of tumorproduced mucins to Siglec-9. Biochem Biophys Res Commun (2010) 402:663-9. doi:10.1016/j.bbrc.2010.10.079

150. Rughetti A, Pellicciotta I, Biffoni M, Backstrom M, Link T, Bennet EP, et al. Recombinant tumor-associated MUC1 glycoprotein impairs the differentiation and function of dendritic cells. J Immunol (2005) 174:7764-72.

Conflict of Interest Statement: The authors declare that the research was conducted in the absence of any commercial or financial relationships that could be construed as a potential conflict of interest. 
Received: 30 September 2013; accepted: 15 December 2013; published online: 27 December 2013.

Citation: Crespo HJ, Lau JTY and Videira PA (2013) Dendritic cells: a spot on sialic acid. Front. Immunol. 4:491. doi: 10.3389/fimmu.2013.00491

This article was submitted to Inflammation, a section of the journal Frontiers in Immunology.
Copyright (c) 2013 Crespo, Lau and Videira. This is an open-access article distributed under the terms of the Creative Commons Attribution License (CC BY). The use, distribution or reproduction in other forums is permitted, provided the original author(s) or licensor are credited and that the original publication in this journal is cited, in accordance with accepted academic practice. No use, distribution or reproduction is permitted which does not comply with these terms. 